\title{
Aşağı Seyhan Ovası Sulama Birliklerinin Kümeleme Analizi ile Karşılaştırılması
}

\author{
Hasan DEĞIRMENCí ${ }^{1}$ \\ Çağatay TANRIVERDi ${ }^{1 / \alpha}$ \\ Firat ARSLAN ${ }^{2}$ \\ ${ }^{1}$ KSÜ Ziraat Fakültesi Biyosistem Mühendisliği Bölümü, Kahramanmaraş \\ ${ }^{2}$ KSÜ Fen Bilimleri Enstitüsü Biyosistem Mühendisliği Bölümü, Kahramanmaraş \\ $\bowtie$ : ctanriverdi@ksu.edu.tr
}

Geliş (Received): 27.12.2016

Kabul (Accepted): 03.02.2017

\begin{abstract}
ÖZET : Performans göstergeleri, sulama birliklerinin eksikliklerini belirlemek ve gerekli önlemleri almak için önemli bir araçtır. Birçok ülkede, sulama sistemlerinin yönetim sorumluluğu sulama birliklerine devredilmiştir. Ancak sulama birliklerinin performansı her sulama birliğinde farklılık göstermektedir. Bu çalışmada Aşağı Seyhan Ovasında faaliyet gösteren 20 sulama birliği I. ürün sulama oranı, II. ürün sulama oranı, yıllık bakım onarım oranı ve ortalama su ücreti göstergeleri kullanılarak kümeleme analizi ile karşılaştırılmıştır. Araştırma sonucunda her bir gösterge için dendogram oluşturulmuştur. Kümeleme analizi, oluşturulan dendogramlar incelendiğinde sulama birliklerinin 3 grup altında toplandığı ve geniş bir varyasyon oluşturduğu görülmüştür. Ayrıca, sulama suyu ücretinin ve yıllık bakım onarım oranının sulama birliklerinin başarısına önemli etki yaptığı belirlenmiştir.
\end{abstract}

Anahtar Kelimeler: Kümeleme Analizi, Performans Göstergeleri, Sulama Oranı, Bakım Onarım Oranı, Sulama Suyu Ücreti

\section{Comparing Lower Seyhan Plain Irrigation Associations by Cluster Analysis}

ABSTRACT : Performance indicators are the key to detect and take pre-cautions for deficiencies of irrigation unions. In many countries, administration of irrigation systems is assigned to irrigation associations. Yet, every single irrigation association differs from each other by performance. In this study, indicators of $1^{\text {st }}$ and $2^{\text {nd }}$ crop irrigation intensities, annual maintenance ratio and average irrigation water fee of 20 active irrigation associations located in Lower Seyhan Plain were used and compared with cluster analysis. Following the study, a dendogram was formed for each indicator. Analysis of dendograms constituted by cluster analysis indicated that irrigation associations were categorized under 3 different groups and varied widely. Also, it was determined that, irrigation water fees and annual maintenance ratios made a substantial contribution to irrigation associations' success.

Keywords: Cluster analysis, performance indicators, irrigation intensity, maintenance ratio, irrigation water fee

\section{GíRiş}

Tarımsal üretimde, sulama verimliliği artıran en önemli faktörlerden birisidir. Ülkemizde bugüne kadar toplam 6.225 milyon hektar arazi sulamaya açılmıştır. DSİ tarafından inşa edilen ve işletilen sulama şebekeleri 1990'lı yılların başından itibaren işletme, bakım ve yönetim sorumluluğunun devrine ilişkin çalışmaları sonucunda çeşitli su kullanıcı örgütlerine devredilmiştir. 2016 yılı Nisan ayı itibariyle devredilen tesislerin toplam sulama alanı 2.324.354 ha'dır. Buna göre 389 adet sulama birliği, toplam devredilen alanın \% 89'una tekabül eden 2.074.510 ha alana hizmet etmektedir (DSİ, 2015). Büyük emek ve harcamalarla gerçekleştirilen sulama şebekelerinin başarısının izlenmesi ve değerlendirilmesi önemli konulardan biridir. Devir sonrası sulama şebekelerinin başarısı üzerine yapılan araştırmalarda istenilen hedeflere tam olarak ulaşılamadığı görülmektedir.

Karşılaştırma ya da kıyaslama: Bir projenin performansını sürekli iyileştirme amaçlı diğer proje performans sonuçları ile karşılaştırarak bir öğrenme sürecidir (Malano ve Burton, 2001). Sulama proje performans iyileştirilmesi için kıyaslama tekniklerinin uygulanması yeni bir olgudur. Bu tekniğin temel amacı sulama şebekelerinin performansını karşılaştırmak ve geliştirmektir. $\mathrm{Bu}$ şekilde hangi uygulamanın hangi sulama şebekesinde daha iyi sonuç verdiği gözlemlenebilir ve iyileştirmeye yönelik tedbirler alınabilir.

Performans göstergeleri bir sistemin bir diğer sistem ile karşılaştırılmasında ana araçlardan birisidir. Performans göstergeleri alan, bitki, su ve finans ile ilgili verilerden elde edilen bir oran ya da sayıdır. Performans göstergeleri ile bir sulama birliğinde ya da şebekesinde düşük ya da yüksek randıman belirlenebilir ve mevcut farklılıklar ortaya konulabilir.

Sulama sistemlerinin etkinliğini ve başarısını ölçmek için bir çok araştırıcı performans göstergeleri geliştirmiş ve uygulamışlardır (Garce's, 1983; Rao, 1993; Molden ve ark., 1998; Burt ve Styles, 2000; Alexander ve Potter, 2004; Malano ve ark., 2004). Ülkemizde de, sulama birliklerinin/şebekelerin performans göstergeleri ile karşılaştırılması ve değerlendirilmesine yönelik çeşitli araştırıcılar tarafindan çalışmalar yapılmış ve yayınlanmıştır (Çakmak, 2001; Degirmenci, 2004; Nalbantoğlu ve Çakmak, 2007; Akkuzu ve Mengü, 2011; Tanrıverdi ve ark., 2011; Aydoğdu ve ark., 2014; Akçay ve Tunal1, 2016).

Sulama birliklerinin/şebekelerinin performanslarını kıyaslamak amacıyla son yıllarda Temel Bileşenler Analizi (Principal Componet Analysis-PCA) ve Kümeleme Analizi (Cluster Analysis) kullanılmaktadır. 
Kümeleme analizi, gruplanmış verileri benzerliklerine göre sınıflandırmada sıklıkla kullanılan çok değişkenli istatistik yöntemlerinden birisidir. Kümeleme analizinin amacı, birey ya da nesnelerin temel özelliklerini dikkate alarak onları gruplandırmaktır. Diğer bir anlatımla gruplanmamış verileri benzerliklerine göre gruplandırarak araştırmacıya özet bilgiler sunmaktadır (Kalayc1, 2009). Kümeleme analizi ile her bir diğer sulama şebekesine göre zayıf ve güçlü noktalar tespit edilebilir, karar vericilere yeni sulama yatırımlarında ya da sulama modernizasyonunda kullanılabilir veriler sunabilir (Rodriguez-Diaz ve ark., 2008).

Sulama şebekelerinin performanslarını karşılaştırmak için son yıllarda kümeleme analizi ile çeşitli araştırıcılar tarafından araştırmalar yapılmış ve yayınlanmıştır. Rodriguez-Diaz ve ark. (2008) ispanya'da sistem işletme, finansal ve verimlilik göstergeleri ile 9 sulama şebekesini kümeleme analizi ile karşılaştırmışlardır. Zema (2015), Kuzey İtalya'da sistem işletme ve finansal performans göstergeleri ile 7 sulama birliğini kümeleme analizi ile karşılaştırmıştır. Geethanjali ve Kumari (2015) Hindistan'da MGNREG sulama şebekesinde işletme sahiplerinin gelir göstergeleri ile kümeleme analizi yapmışlardır. Hashemy ve Monem (2012) İran'da bir sulama şebekesinin işletme ve bakım faaliyetlerini ana, sekonder ve tersiyer kanalları kümeleme analizi ile karşılaştırmışlardır. Ngiraziea ve ark. (2015) Sudan GASH sulama sahasında faaliyet gösteren sulama birliklerini kümeleme analizi ile değerlendirmişlerdir. Bareng ve ark. (2015) Filipinlerde Cagayan Nehir Havzasında 2008-2012 yılları verilerine göre sistem işletme performansı, tarımsal verimlilik ve ekonomi, finansal göstergelerle kümeleme analizi ile karşılaştırma yapmışlardır. Hussain ve ark. (2008) Batı Suudi
Arabistan'da bir sulama şebekesindeki sulama suyunun kalitesini kümeleme analizi ile değerlendirmişlerdir.

$\mathrm{Bu}$ çalışmanın amacı, Aşağı Seyhan Ovasında bulunan 20 Sulama Birliğinin 2010-2015 y1lları verilerinden hesaplanan I. Ürün Sulama Oranı, II. Ürün Sulama Oranı, Bakım Onarım Oranı ve Ortalama Su Ücretleri göstergeleri kullanılarak kümeleme analizi ile karşılaştırılmasının yapılmasıdır. Ek olarak bu 6 yıllık dönem içerisinde belirlenen tüm göstergelerin ortalama, minimum ve maksimum değerlerinin grafiklerle analiz edilmesidir.

\section{MATERYAL ve YÖNTEM}

\section{Materyal}

Aşağı Seyhan Ovasında (ASO) faaliyet gösteren 20 Sulama Birliği araştırmanın materyalini oluşturmaktadır. Araştırma kapsamında I. Ürün, II. Ürün ekim alanları, bakım onarım masrafları ve su ücretlerine ilişkin veriler Sulama birliklerinin 2010-2015 yılları arasındaki izleme ve değerlendirme raporlarından alınmıştır. Sulama birlikleri sorumluluk alanındaki sulama alanları ve en fazla ekimi yapılan bitkiler Çizelge 1 'de verilmiştir. Çizelge 1'de görüldüğü gibi 20 sulama birliği değerlendirildiğinde en fazla ekimi yapılan bitkilerde Misır ve Narenciye'dir.

ASO proje alanı, Akdeniz Bölgesinde, kuzeyde Toros Dağlarının etekleri, batıda Berdan Nehri, güneyde Akdeniz, doğuda Ceyhan Nehri ile sınırlanan 210.000 ha genişliğindeki sahadır (Şekil 1). Saha kuzeyden güneye Seyhan Nehri ile ikiye bölünür. Seyhan Nehri ile Berdan Nehri arasında kalan bölge Seyhan Sağ Sahil veya Tarsus Ovası, Seyhan nehri ile Ceyhan Nehri arasında kalan bölge de Seyhan Sol Sahil veya Yüreğir Ovası olarak adlandirılır.

Çizelge 1.20 Sulama Birliğinde Sulama Alanları ve Ekim Yapılan Bitkiler

\begin{tabular}{|l|l|l|l|}
\hline $\begin{array}{l}\text { Birlik } \\
\text { Sayısı }\end{array}$ & Birlik Adı & Sulama Alanı (ha) & $\begin{array}{l}\text { En Çok Ekimi Yapılan } \\
\text { Bitkiler }\end{array}$ \\
\hline 1 & Cumhuriyet & 2655 & Misır, Narenciye \\
\hline 2 & Çotlu & 2425 & Misır, Patates \\
\hline 3 & Kuzey Yüreğir & 4860 & Misır, Patates \\
\hline 4 & Y.Akarsu & 8943 & Misır, Narenciye \\
\hline 5 & Güney Yüreğir & 16890 & Misır, Pamuk \\
\hline 6 & Gazi (Onüçköy) & 6394 & Misır, Narenciye \\
\hline 7 & Yenigök & 1864 & Misır, Pamuk \\
\hline 8 & Gökova & 4289 & Narenciye, Misır \\
\hline 9 & Kadıköy & 9808 & Misır, Narenciye \\
\hline 10 & Altınova & 6150 & Misır, Narenciye \\
\hline 11 & Çukurova & 6847 & Misır, Narenciye \\
\hline 12 & Pamukova & 12037 & Misır, Narenciye \\
\hline 13 & Seyhan & 3610 & Misır, Soya \\
\hline 14 & Tarsus Onköy & 11983 & Misır, Soya \\
\hline 15 & Toroslar & 13700 & Misır, Narenciye \\
\hline 16 & Yeşilova & 3740 & Misır, Soya \\
\hline 17 & Handeresi & 819 & Yerfistı̆̆, Misır \\
\hline 18 & Karaisalı & 2186 & Misır, Ayçiçeği \\
\hline 19 & Aflak-Çiçekli Sul. Kop. & 1870 & Misır, Sebze \\
\hline 20 & Kilıçlı (Adana Sul. Bir.) & 825 & Misır, Narenciye \\
\hline
\end{tabular}




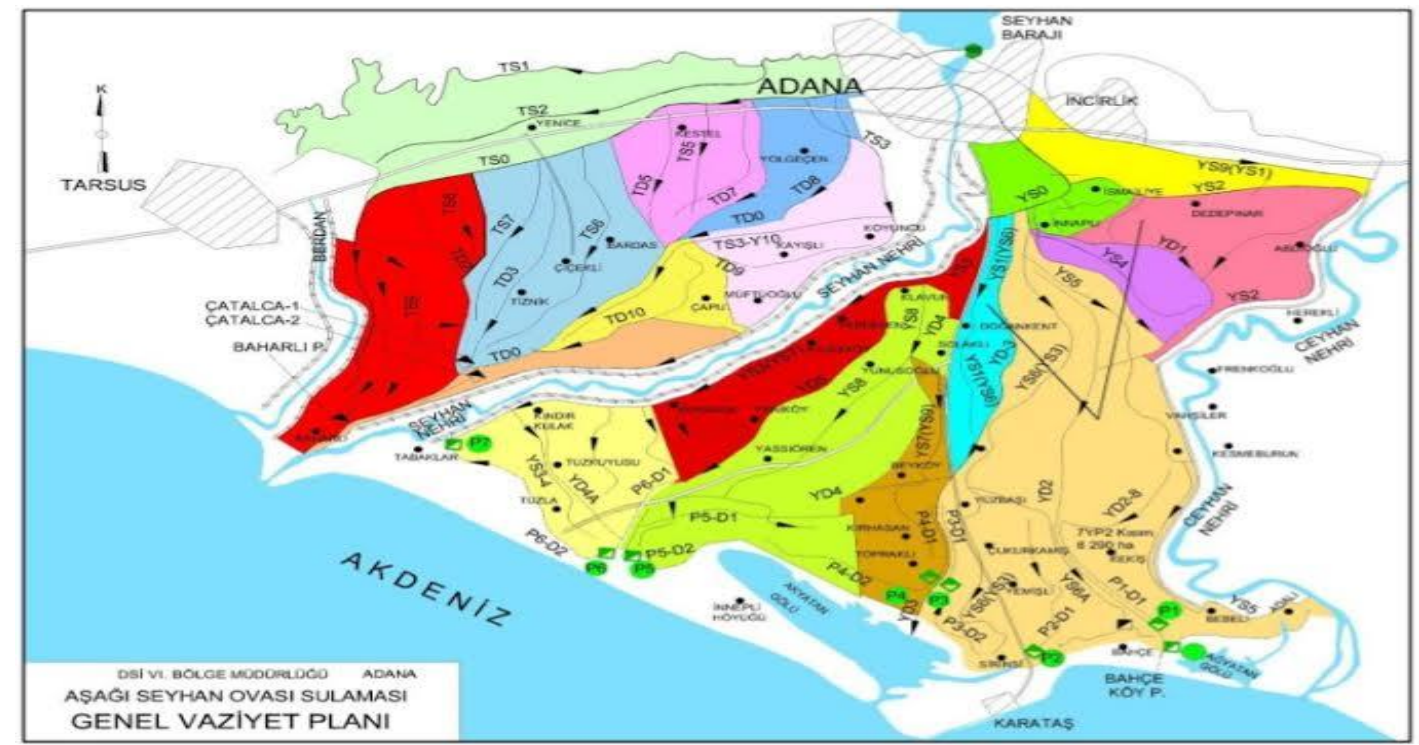

Şekil 1. Aşağı Seyhan Ovası Sulama Sahası

Yöntem

Araştırma kapsamında 2010-2015 yılları için sulama birliklerinin sorumluluk alanında yer alan sulama şebekelerinin I. Ürün Sulama Oranı, II. Ürün Sulama
Oranı, Bakım Onarım Oranı ve Ortalama Su Ücreti göstergeleri kullanılmıştır. $\mathrm{Bu}$ göstergelerin hesaplanmasına ilişkin formüller Eşitlik 1, 2, 3 ve 4'de verilmiştir.

$$
\begin{aligned}
& \text { I. Ürün Sulama Oranı }(\%)=\frac{\text { Yllllk I.Ürün Sulanan Alan }(h a)}{\text { Sulama Alanı }(h a)} X 100 \\
& \text { II. Ürün Sulama Oranı }(\%)=\frac{\text { Ylllk II.Ürün Sulanan Alan }(\text { ha })}{\text { Sulama Alanı }(\text { ha })} X 100 \\
& \text { Bakım Onarım Oranı }(\%)=\frac{\text { Ylllık Bakım Onarım Gideri } *(T L)}{\text { Ylllı Gelir** }(T L)} X 100 \\
& \text { Ortalama Su Ücreti }(T L d a 1)=\frac{\text { DekarXTL(her ürün için farkll })+T L X m 3}{2}
\end{aligned}
$$

*Yıllık Bakım Onarım Gideri: Kanallarda beton, sanat yapıları onarımları, ana, sekonder, tersiyer ve drenaj kanallarının temizlikleri, kanalet onarımları, çek priz kapaklarının boyanması, servis yolları bakımı vb. giderleri

**Yıllık Gelir: Su ücretleri, katılım payları, kurum/örgüt malları gelirleri, para cezaları, faiz gelirleri

***Y1ll1k Su ücreti: Bir sulama birliğinde her ürün için dekar X TL şeklinde olduğu gibi bazı şebekelerde $\mathrm{m}^{3} \mathrm{X}$ TL ya da her ikisi de uygulanmaktadır.

Değerlendirmeye alınan Sulama birliklerinin 6 yıllık dönem içerisindeki ortalama, minimum ve maksimum değişimini gösteren grafikler ise Excel hesap tabloları yardımı ile yapılmıştır.

\section{Kümeleme Analizi}

Kümeleme analizi, bir gözlemler setini grup veya kümelerin sınırlı bir sayısına ayırmayı amaçlayan çok değişkenli bir istatistik yöntemidir (Neil, 2002). Kümeleme analizinde değişkenler gösterdikleri özellikler kullanılarak karşılaştırılır (Kalaycı, 2009).

Kümeleme analizinde ilk aşama, bir benzerlik veya uzaklık ölçüsünün (kareli öklid uzaklık veya pearson korelasyon gibi) seçilmesidir (Öz ve ark., 2009). Sonra kullanılacak kümeleme tekniğine (hiyerarşik veya hiyerarşik olmayan gibi) yönelik bir karar verilir. Üçüncü adımda seçilen teknik için kullanılacak olan kümeleme yöntemi türü (hiyerarşik kümeleme tekniğinde Ward's yöntemi gibi) seçilir. Son aşamada ise küme sayısı belirlenerek kümeleme sonucu yorumlanır (Sharma, 1996).

Kümeleme işlemi, Hiyerarşik kümeleme ve hiyerarşik olmayan kümeleme olarak iki şekilde yürütülür. En çok kullanılan yöntemler, hiyerarşik yöntemler grubudur (Kalaycı, 2009). Bu çalışmada da incelenen göstergenin az sayıda olmasından dolayı birbirine benzer sulama birliklerini belirleyebilmek amacıyla hiyerarşik kümeleme analizi kullanılmıştır.

Hiyerarşik kümeleme yöntemi bütün gözlemleri tek bir kümede toplar; sonra bu kümeye en aykırı olan gözlemleri birer birer kümeden ayırarak başka kümelerin oluşmasını sağlar. Yöntem kaç tane küme oluşması gerektiğine kendisi karar verebilir. Hiyerarşik kümeleme analizinde kümeleri birleştirebilmek amacıyla birçok bağlantı yöntemi (linkage method) mevcuttur. Bu çalışmada varyans yöntemi (Ward's Yöntemi) kullanılmıştır. Varyans yöntemi, bir kümenin ortasına düşen gözlemin, aynı kümenin içinde bulunan gözlemlerden ortalama uzaklığı esas alır. Toplam sapma karelerinden yararlanılır (Kalaycı, 2009).

$\mathrm{Bu}$ çalışmada, sulama birliklerinin hangi sınıflara kümelendiği kümeleme analizi ile ve küme sayısı belirleme işlemi de dendogram (Ağaç grafiği) 
yardımıyla yapılmıştır. Dendogram kümeleme analizi sonuçlarının grafiksel bir özetidir. Dikey eksen sulama birliklerini ve yatay eksen ise kümeler arasındaki uzaklıkları göstermektedir.

\section{BULGULAR ve TARTIŞMA}

I. Ürün Sulama Oranı (\%)

Değerlendirme kapsamında 2010-2015 yılları verilerine göre sulama birliklerinin I. Ürün sulama oranlarına ilişkin dendogram Şekil 2'de, ortalama, minimum ve maksimum değerleri gösteren grafik ise Şekil 3'de verilmiştir. Şekil 2'de verilen dendogram incelendiğinde sulama birliklerinin 3 grup oluşturduğu görülmektedir. 1. ve 2. Grupta yer alan sulama birliklerinin birbirine yakın sonuçlar oluşturduğu görülmektedir. Yine Şekil 2 incelendiğinde özellikle 3. grupta yer alan Handeresi ve Karaisalı sulama birliklerinin I. ürün sulama oranları yönünden diğerlerinden ayrıldığı görülmektedir. Şekil 3'de verilen grafikte de anlaşıldığ 1 gibi en düşük I. ürün sulama oranlarının bu sulama birliklerinde gerçekleştiği görülmektedir. Ayrıca Şekil 3'de bazı yıllarda I. ürün sulama oranlarının Y. Akarsu, Gökova, Seyhan ve Toroslar sulama birliklerinde \%100'e ulaştığı görülmektedir.

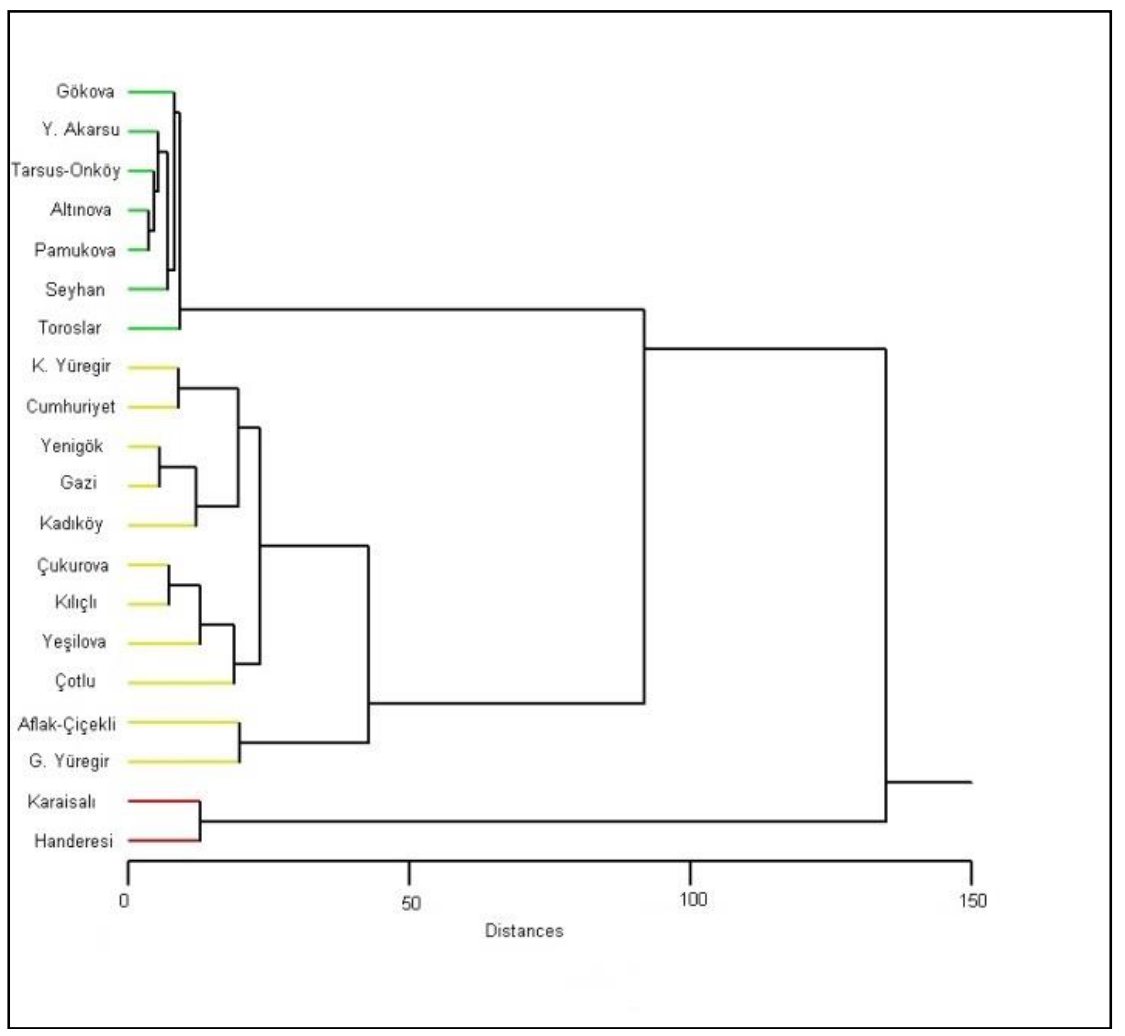

Şekil 2. I. Ürün Sulama Oranına Göre Sulama Birlikleri Dendogramı

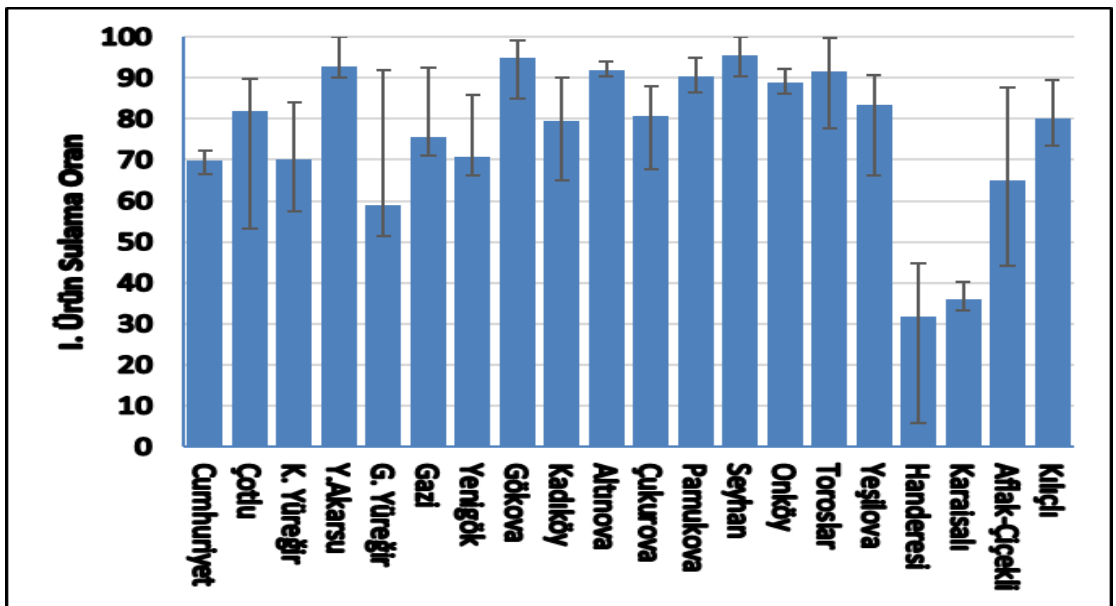

Şekil 3. I. Ürün Sulama Oranı Ortalama, Minimum ve Maksimum Değerleri 


\section{II. Ürün Sulama Oranı (\%)}

II. ürün sulama oranlarına ilişkin dendogram Şekil 4'de verilmiştir. Dendogramda görüldüğü gibi II. ürün sulama oranı \%1'den fazla olan 16 sulama birliği değerlendirmeye alınmıștır. ASO sulama şebekelerinin bazılarında ya çok az ya da hiç II. ürün ekimi yapılmamaktadır. Yapılan değerlendirmelerde Dendogram incelendiğinde 3 grubun oluştuğu görülmektedir (Şekil 4). Uzun yıllık veriler dikkate alındığında, Seyhan, Kadıköy ve Aflak-Çiçekli sulama birliklerinin 1. grubu oluşturduğu anlaşılmaktadır. 2. grupta ise Gökova, Altınova, Cumhuriyet ve Yeşilova sulama birliklerinin yer aldığı görülmektedir. Diğer sulama birlikleri ise 3. grubu oluşturmaktadır. Şekil 5 incelendiğinde maksimum değerin Aflak-Çiçekli sulama birliğinde, ortalama değerin ise sirasıly Seyhan ve Kadıköy sulama birliklerinde gerçekleştiği anlaşılmaktadır.

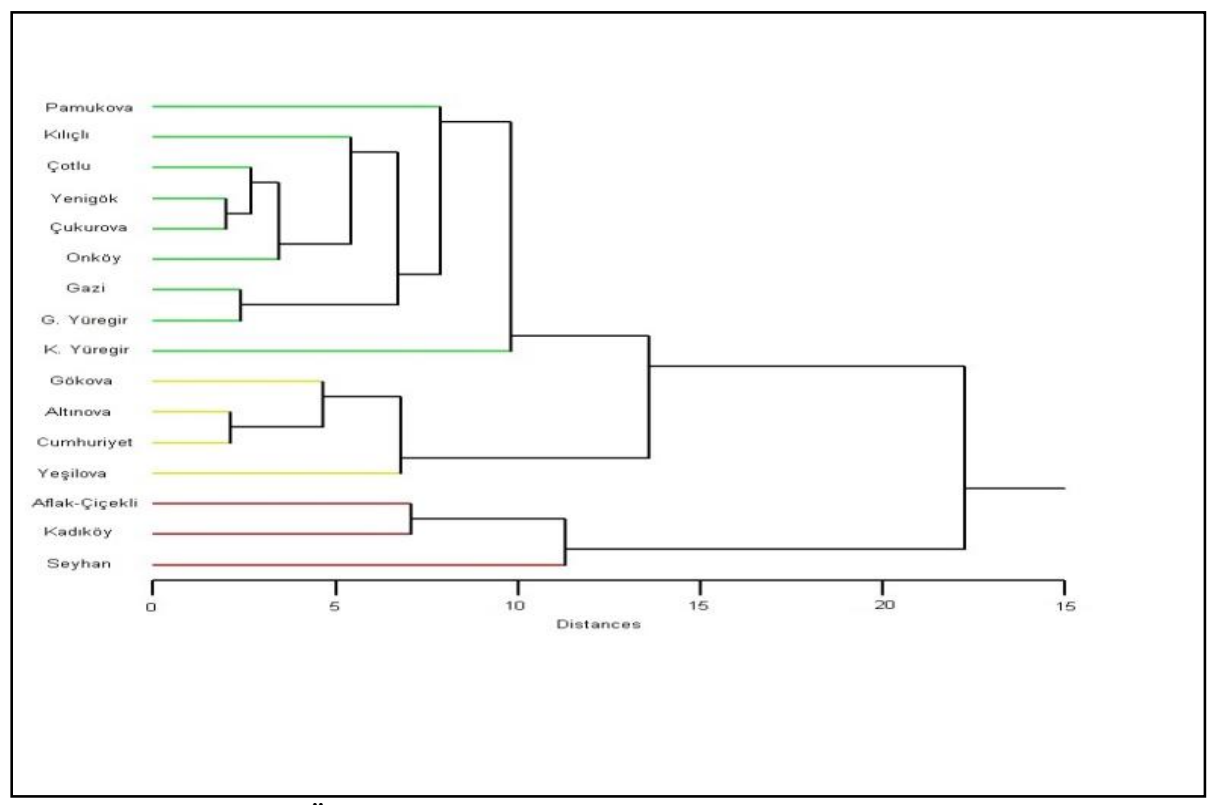

Şekil 4. II. Ürün Sulama Oranına Göre Sulama Birlikleri Dendogramı

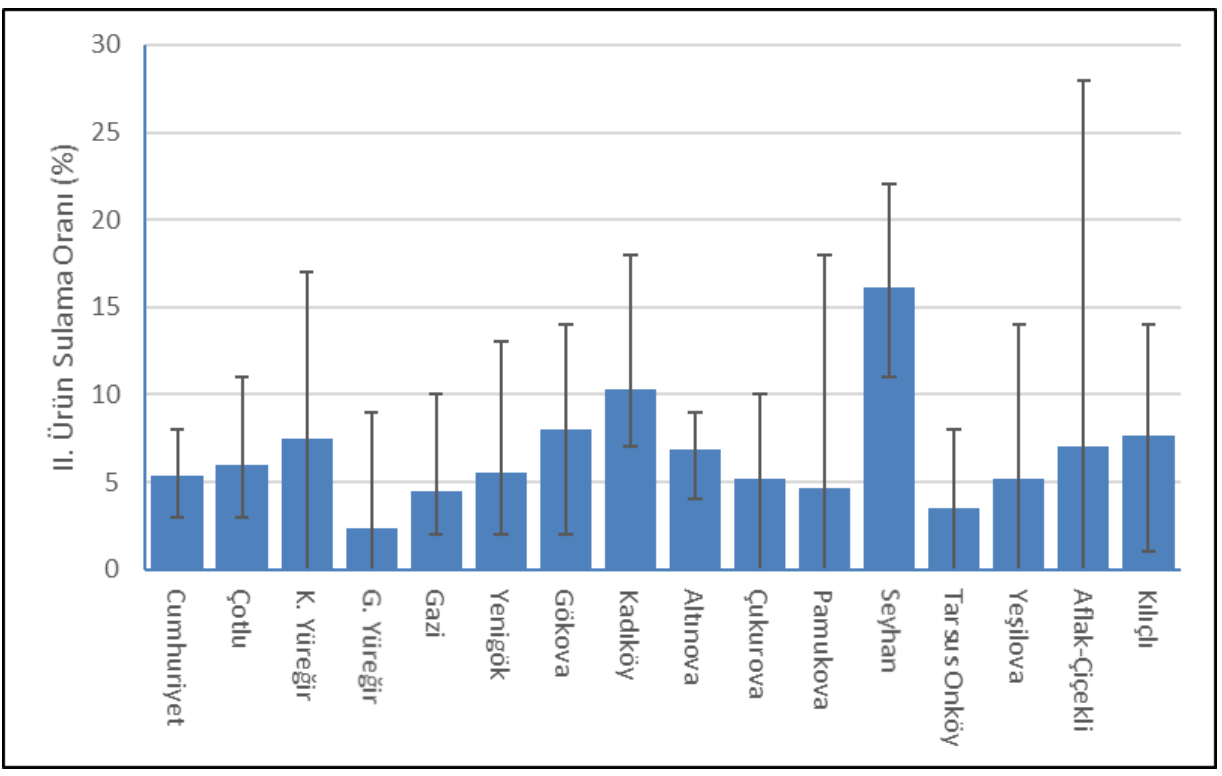

Şekil 5. II. Ürün Sulama Oranı Ortalama, Minimum ve Maksimum Değerleri 


\section{Bakım Onarım Oranı (\%)}

Sulama birlikleri yıllık gelirin ne kadarını bakım onarıma harcadığını belirlemek için hesaplanan bakım onarım oranlarına ilişkin dendogram Şekil 6'da verilmiştir. Bakım onarım oranına göre iki grup oluştuğu görülmektedir. 1. grupta Kadıköy, Onköy, Kılıçlı, G.yüreğir ve Altınova sulama birliklerinin yer aldığ görülmektedir. 2. grupta ise diğer sulama birliklerinin yer aldığı görülmektedir. Yıllık bakım onarım oranı değerleri ortalama, minimum ve maksimum olarak Şekil 7'de verilmiştir. 6 yıllık verilere göre şekil incelendiğinde, en fazla ortalama bakım onarım oranının Altınova ve $G$. Yüreğir sulama birliklerinde, maksimum oranın ise Pamukova ve Kılıçlı sulama birliklerinde gerçekleştiği görülmektedir. En düşük bakım onarım oranının sırasıyla Ata, Cumhuriyet ve Karaisalı sulama birliklerinde bulunmuştur.

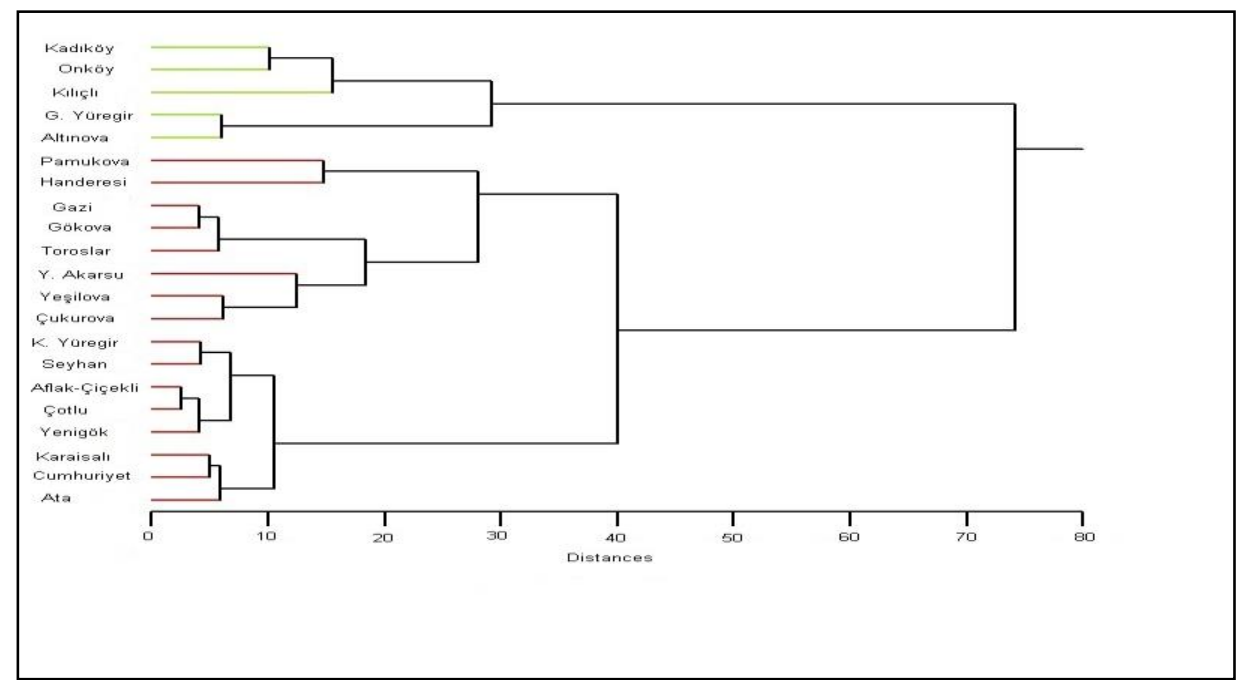

Şekil 6. Yıllık Bakım Onarım Oranı Dendogramı

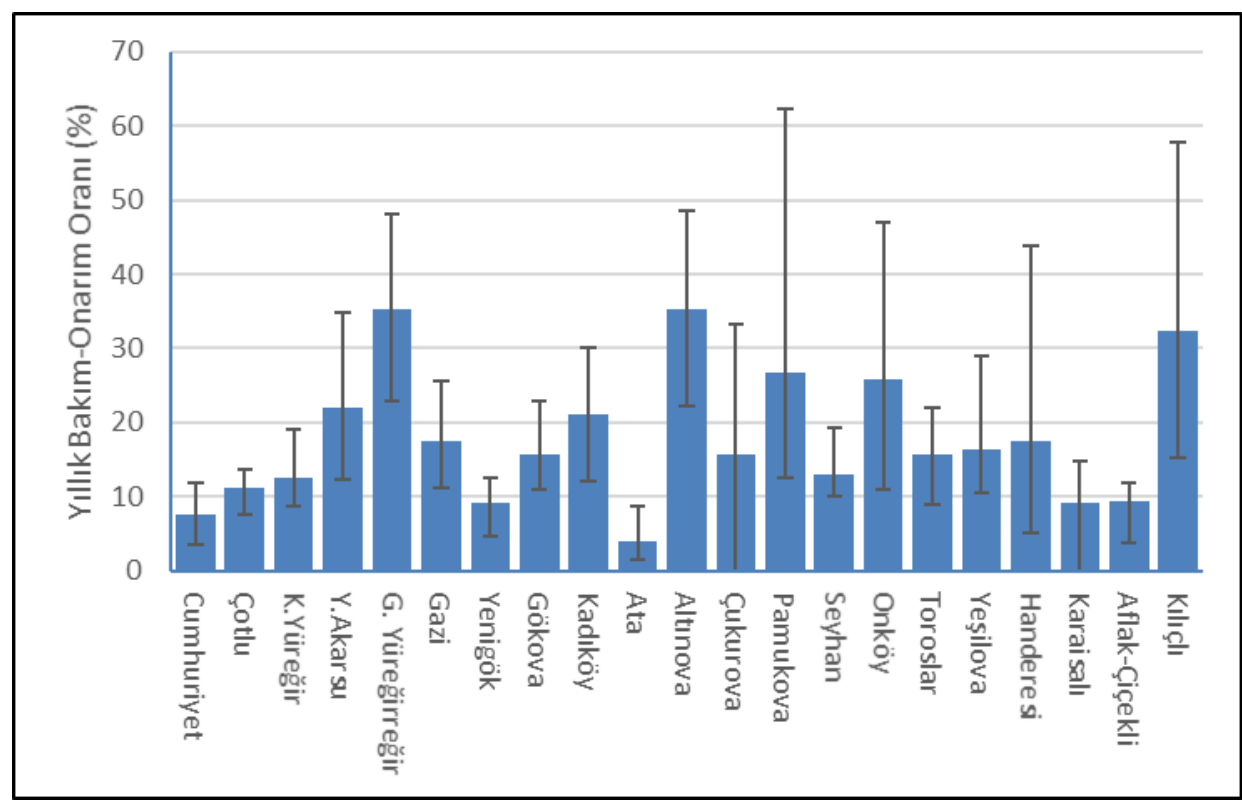

Şekil 7. Yıllık Bakım Onarım Oranı Ortalama, Minimum ve Maksimum Değerleri

Yıllık Ortalama Sulama Suyu Ücreti (TL da-1)

Y1llı ortalama sulama suyu ücretlerine ilişkin kümeleme analizi sonuçlarına ilişkin dendogram Şekil 8 'de, ortalama, minimum ve maksimum değişimi gösteren değerler ise Şekil 9'da grafik ile gösterilmiştir. Şekil 8'de yıllık ortalama sulama suyu ücretlerine ilişkin dendogramda 2. grup oluştuğu görülmektedir.
Değerlendirmeye alınan sulama birlikleri içinde Cotlu, Handeresi, Cumhuriyet ve Kılıçlı sulama birliklerinin 1. grubu oluşturduğu görülmektedir. $\mathrm{Bu}$ dört sulama şebekesinde sulama suyu ücretlerinin birbirine yakın olduğu ve diğerlerine göre yüksek olduğu görülmektedir. Değerlendirmeye alınan diğer sulama birliklerinin ise 2 . grupta yer aldığ 1 görülmektedir. Şekil 9 incelendiğinde 6 
y1llık dönem içerisinde maksimum değerin Çotlu sulama birliğinde, en düşük değerin ise Ata sulama birliğinde

gerçekleştiği görülmüştür.

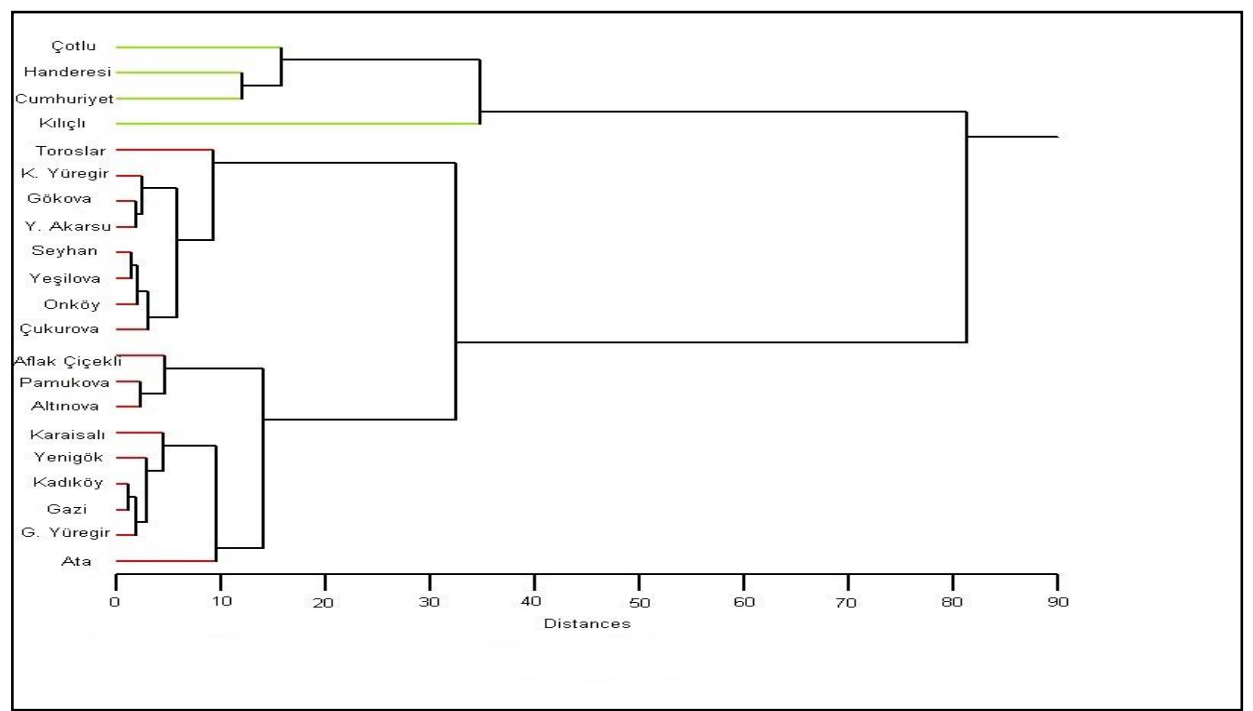

Şekil 8. Y1llık Ortalama Sulama Suyu Ücreti (TL/da) Dendogramı

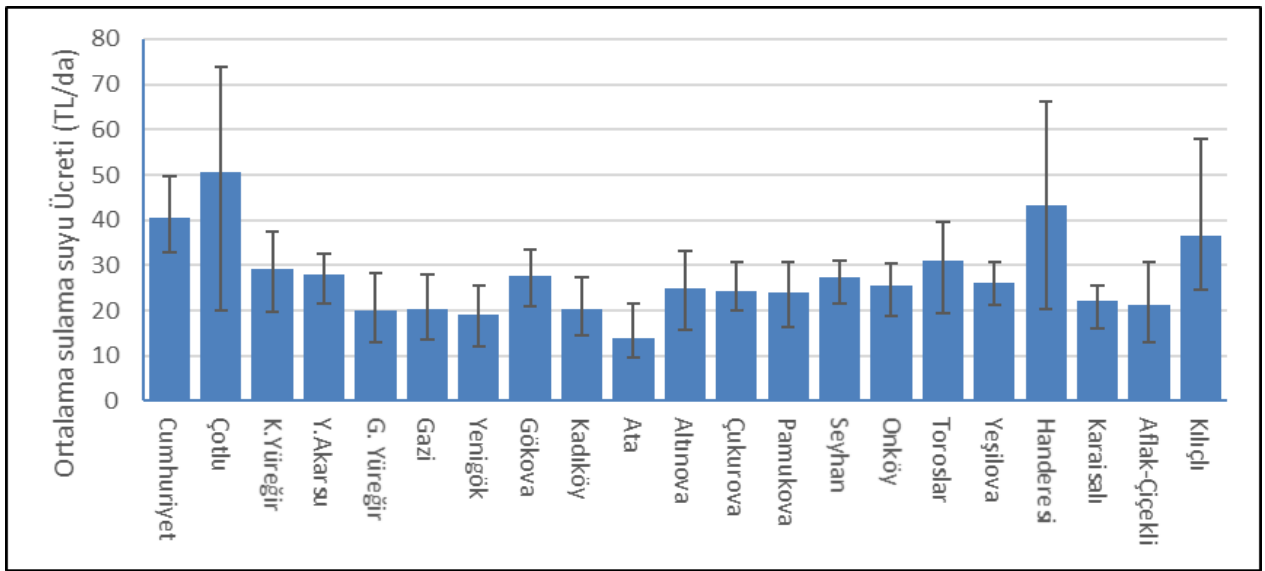

Şekil 9. Yıllık Sulama Suyu Ücreti (TL/da) Ortalama, Minimum ve Maksimum Değerleri

\section{SONUC}

Yapılan bu çalışmada ortaya çıkan sonuçlar toplu olarak değerlendirildiğinde I. ürün sulama oranı düşük olan Handeresi gibi sulama birliklerinde sulama suyu ücretinin çok yüksek olduğu gözlemlenmiştir. Aynı zamanda, sulama suyunun sulama oranına doğrudan etkili olduğu bulunmuştur. Ek olarak da, bakım onarım oranının yüksek olduğu Ata, Cumhuriyet, Aflak-Çiçekli, Karaisalı, Yenigök ve Çotlu sulama birliklerinde II. Ürün sulama oranının yüksek olduğu görülmektedir. Sulama şebekelerinin uzun ve kısa dönemde başarısına en etkili faktörlerden birside yıllık gelirden bakım onarım giderine ayrılan orandır. Çalışmada beklenen bir sonuç olarak bakım onarım oranı arttıça sulama oranı yükselmekte, sulama suyu ücretleri de düşmekte olduğu ortaya çıkmıştır. Ata sulama birliği şebeke dışı bir birlik olduğundan en düşük sulama suyu ücreti bu sulama birliğinde uygulanmakta olduğu belirlenmiştir. Sulama suyu ücretinin yüksek olduğu Çotlu, Handeresi,
Cumhuriyet ve Kılıçlı sulama birliklerinde, II. ürün sulama oranlarının da düşük gerçekleştiği görülmektedir. Bütün bu değerlendirmeler neticesinde, sulama birliklerinin başarısında yıl içerisindeki faaliyetlerin doğrudan etkili olduğu ve her bir faktörün diğerini doğrudan etkilediği görülmektedir. Özellikle sulama suyu ücretinin yüksekliği II. ürün ekim alanını kısıtlarken, bakım onarım oranının yüksek olduğu birliklerde ise hem I. ürün ekim alanlarında hem de II. ürün ekim alanlarında artış olduğu görülmektedir.

Araştırma sonucunda, ASO sulama birliklerinin gelirgider oranlarının I. ürün ve II. ürün ekim alanları yönünden oldukça başarılı oldukları görülmektedir. Özellikle Handersi ve Karaisalı sulama şebekelerinin iyileştirilmesi yönünde gerekli çalışmaların yapılması gerekmektedir. Güney Yüreğir sulama birliğinde sulama suyu ücreti düşük olmasına rağmen, hem I. ürün hem de II. ürün sulama oranı oldukça düşük gerçekleşmiştir. Bu sulama birliğinin sorumluluk sahasında sulama oranının 
artırılması için de gerekli çalışmaların başlatılması gerekmektedir. Aynı zamanda, bölgede bulunan sulama birliklerinin gelirlerinin büyük bir kısmını sulama şebekelerinin modernizasyonu için ayrılması oldukça önemli olduğu belirlenmiştir. Bölgede bulunan sulama şebekeleri açık kanal sulama sistemlerine sahiptir. Bu nedenle, şebekelerin modernizasyonu ve toplu basınçlı sulama sistemlerinin uygulanmasına yönelik çalışmalar yapılması gereği de belirlenmiştir.

\section{KAYNAKLAR}

Akçay S, Tunalı SP 2016. Aşağı Büyük Menderes ve Aşağ Gediz Havzası Sulama Birliklerinin Üretim ve Su Kullanım Performanslarının Karşılaştırmalı Olarak Değerlendirilmesi. Türkiye Tarımsal Araştırmalar Dergisi, 3(1), 64-73.

Akkuzu E, Mengü GP 2011. Alaşehir Yöresi Sulama Birliklerinin Arazi-Su Verimliliği ve $\mathrm{Su}$ Temini Açısından Değerlendirilmesi. Ege Üniversitesi Ziraat Fakültesi Dergisi, 48(2), 119-126.

Alexander P, Potter M 2004. Benchmarking Of Australian Irrigation Water Provider Businesses. Irrigation and Drainage, 53(2004), 165-173.

Aydoğdu MH, Karlı, B, Yenigün K, Mancı AR 2014. Harran Ovasındaki Sulama Birliklerinin Yapısal Sorunları ve Çözüm Önerileri. Tarım Bilimleri Dergisi 2001, 7(3), 111-117.

Bareng JLR, Balderama OF, Alejo LA 2015. Analysis of Irrigation Systems Employing Comparative Performance Indicators: A Benchmark Study for National Irrigation and Communal Irrigation Systems in Cagayan River Basin. Journal of Agricultural Science and Technology A, 325.

Burt CM, Styles SW 2000. Modern water control and management practices: impact on performance. Water Report 19, FAO.

Çakmak B 2001. Konya Sulama Birliklerinde Sulama Performansının Değerlendirilmesi. Tarım Bilimleri Dergisi 2001, 7(3), 111-117.

Değirmenci H 2004. Kahramanmaraş Bölgesinde Bazı Sulama Şebekelerinin Karşılaştırma Göstergeleri İle Değerlendirilmesi. Kahramanmaraş Sütçü İmam Üniversitesi Fen ve Mühendislik Dergisi, 7(1), 104-110.

DSİ 2015. Devlet Su İşleri Genel Müdürlüğü 2015 Yılı Faaliyet Raporu. http://www.dsi.gov.tr/docs/stratejikplan/dsi-2015-faaliyet-raporu.pdf?sfvrsn=2\#page $=71$ (Erişim tarihi: 01.06.2016).

Garcés C 1983. A Methodology To Evaluate The Performance of İrigation Systems. Application to Philippine National Systems. Doktora tezi. Cornell University, Ph.D thesis, Ithaca, New York, USA.

Geethanjali CH, Valli Kumari V 2015. A Clustering Based Performance Evaluation System for MGNREG Scheme. International Journal of Advanced Research in Computer and Communication Engineering, Vol. 4, Issue 9,
Hashemy SM, Monem MJ 2012. Facilitation of operation and maintenance activities of irrigation networks using ak-means clustering method: case study of the ghazvin irrigation network. Irrigation and Drainage, 61(1), 31-38.

Hussain M, Ahmed SM, Abderrahman W 2008. Cluster analysis and quality assessment of logged water at an irrigation project, eastern Saudi Arabia. Journal of Environmental Management, 86(1), 297-307.

Kalaycı Ş 2009. SPSS uygulamalı çok değişkenli istatistik teknikleri. Vol. 2. Asil Yayın Dağıtım.

Malano H, Burton M 2001. Guidelines for benchmarking performance in the irrigation and drainage sector. In: International Programme for Technology and Research in Irrigation and Drainage, 2001.

Malano H, Burton M, Makin I 2004. Benchmarking performance in the irrigation and drainage sector: a tool for change Irrigation and Drainage, 53 (2004), 119-133.

Molden DJ, Sakthivadivel R, Perry CJ, de Fraiture CY, Kloezen W 1998. Indicators For Comparing Performance of Irrigated Agricultural Systems. International Water Management Institute, Research Report 20, Colombo, Sri Lanka.

Nalbantoğlu G, Çakmak B 2007. Akıncı Sulama Birliğinde Sulama Performansının Karşılaştırmalı Değerlendirilmesi. Tarım Bilimleri Dergisi 2007, 13(3), 213-223.

Neil TH 2002. Applied Multivariate Analysis. Secaucus, NJ, USA: Springer-Verlag New York.

Ngirazie LA, Bushara AI, Knox JW 2015. Assessing the performance of water user associations in the Gash Irrigation Project, Sudan.Water International, 40(4), 635-646.

Öz B, Taban S, Kar M 2009. Kümeleme Analizi ile Türkiye ve $A B$ Ülkelerinin Beşeri Sermaye Göstergeleri Açısından Karşılaştırılması. Eskişehir Osmangazi Üniversitesi Sosyal Bilimler Dergisi, 10(1).

Rao PS 1993. Review of Selected Literature on Indicators of İrigation Performance. International Irrigation Management Institute, IIMI Research Paper No. 13, Colombo, Sri Lanka.

Rodríguez-Díaz JA, Camacho-Poyato E, Lopez-Luque R, Pérez-Urrestarazu L 2008. Benchmarking and multivariate data analysis techniques for improving the efficiency of irrigation districts: an application in Spain. Agricultural systems, 96(1), 250-259.

Sharma S 1996. Applied Multivariate Techniques. John Wiley and Sons Inc., Canada.

Tanriverdi C, Değirmenci H, Sesveren S 2011. Assessment of Irrigation Schemes in Turkey Based on Management Types. African Journal of Biotechnology, 10(11), 1997 2001.

Zema DA, Nicotra A, Tamburino V, Zimbone SM 2015. Performance Assessment Of Collective Irrigation In Water Users' Associations Of Calabria (Southern Italy). Irrigation and Drainage, 64(3), 314-325. 